\title{
Fiction as feminist pedagogy: an examination of curriculum and teaching strategies embodied in the novel
}

\author{
Christine Jarvis, University of Huddersfield
}

VCO, University of Huddersfield, Queensgate, Huddersfield, HD1 3DH, UK

\section{(+44) 01484471503}

\section{c.a.jarvis@hud.ac.uk}

\begin{abstract}
This article argues that fiction can operate as a critical feminist curriculum and discusses how this manifests itself in terms of content and teaching methodologies. It uses a close reading of Naomi Alderman's dystopian fiction The Power (2016) to explore this, complemented by an analysis of a discussion between Alderman and readers participating in a book club organised through the UK discussion forum Mumsnet. It concludes that fiction can stimulate learning and critical reflection, in this instance with respect to gender and power, thus functioning as critical feminist pedagogy.
\end{abstract}

Key words: dystopian fiction, critical feminist pedagogy, critical curriculum, fiction and adult education, Naomi Alderman

\section{Introduction}

Adult educators have argued that we learn through reading fiction (Jubas, Taber, and Brown 2015). This article aims to examine this argument, by analysing in detail how a specific fiction uses literary and rhetorical strategies as part of an educative process. Whilst the general point that fiction is pedagogy is well rehearsed, the specific ways texts operate pedagogically have received less detailed scrutiny. Different fictions offer different curricula and use many different teaching strategies in the form of structural and literary devices. It is valuable to continue to explore and analyse these processes as they manifest themselves in specific fictions, so that educators can build deep and detailed understandings of the contribution of fiction to adult learning.

The article takes Naomi Alderman's novel, The Power, as a case study, to illustrate how a novel operates as critical feminist pedagogy. It includes analyses of posts from the UK internet forum, Mumsnet (2017a, 2017b), where The Power is discussed, to illustrate the kinds of critical engagement fiction can engender. I begin with background information about the novel and Mumsnet, then outline the theoretical framework for the article, which combines critical feminist 
pedagogy and reader-response theory, whilst acknowledging the article's relationship to the wider body of literature exploring fiction and adult education. An outline of the methodology follows, including consideration of ethical issues relating to analysing postings from public fora. The findings section is divided into three areas: the first considers Alderman's standpoint as a feminist educator, the second focuses on the novel's use of gender reversal to illustrate how this artistic strategy works as pedagogy, and the third discusses how readers are challenged by the novel to reflect on themselves and their understanding of gender.

\section{Background}

The Power is set thousands of years in the future. Women dominate society and possess a 'skein' an organ below the collarbone generating powerful electrical charges. Religion centres on The Mother, the female face of the deity. A devastating event - 'The Cataclysm' - destroyed earlier civilisation, and people believe women have always dominated and had skeins. The Power takes the form of a novel by a male archaeologist, who thinks the conclusions suggested by his archaeological work will be more acceptable as fiction. He believes men once dominated and the evolution of skeins enabled women to seize control. He reconstructs the period when this happened from the perspective of different characters: Tunde, a male journalist; Roxy, the British daughter of a criminal family; Allie, an abused US teenager and Margot, a US politician. The novel received considerable critical acclaim, won the Baileys Women's Prize for Fiction and dominated bestseller lists.

Mumsnet is a UK digital discussion forum, operating since 2000. Discussions are often family focused, but also cover education, feminism and books. It claims 12 million unique visitors per month (Mumsnet, 2017a). Pederson and Smithson state it is 'characterised by a robust use of language and a celebration of confrontational, opinionated, literate and well-informed debate' $(2013,97)$. Forms of digital communication are increasingly significant as pedagogical spaces for adults. Cochran (2014) uses the metaphors of transubstantiation to convey how viewers changed through online engagement with Joss Whedon's work and Hills (2015) examines Doctor Who fans as a digital community of practice, drawing on Wenger's 1998 definition. Jensen and Helles (2011) suggest the internet is 'displacing television as the most widely shared cultural forum' (530). Sedo (2003) examined face-to-face and virtual book clubs, and discovered differences in motivation between participants, with those engaged in virtual clubs attracted by open access policies, flexibility of attendance and the possibility of engaging with wide-ranging views. Eynon and Helsper (2011, 534) note that adult digital participation increases when linked to adults' 'everyday interests' (such as reading books). I use the discussion of the online book club to complement the analysis of the novel by showing how readers reflect on and are challenged by ideas in the novel; I do not explore online learning practices as such. The book discussion group discussed in this article took place on Mumsnet between $16^{\text {th }}$ December 2016 and the $10^{\text {th }}$ February 2017 (Mumsnet, 2017b). The live web chat with Alderman occurred in January 2017.

\section{Theoretical frameworks}

I view the potential pedagogical impact of a text such as The Power on adult readers through two intersecting theoretical lenses: critical feminist pedagogy and reader-response theory. The article sits, however, within a wider literature on fictions and adult education which provides context rather than a specific theoretical framework, and I begin with a summary of this. 
Adult educators use fiction in conventional adult education settings, recognising that it can stimulate critically reflective learning (Jarvis 2006; Jubas 2005; Pandey 2012). Hoggan and Cranton (2015) used a short story to promote critical reflection on transformative learning. Fiction can stimulate awareness of inclusivity and social justice (Gouthro and Holloway 2013; Green 2013; Tisdell 2008) and promote critical engagement with the values and power dimensions of professions, such as health professions (Kinsella 2007) and teaching (Wright and Wright 2013). Although this article focuses on learning outside educational institutions, this broader literature demonstrates that fictional texts can be part of an institution-based curriculum that challenges assumptions and critiques power.

In this article I discuss the pedagogical potential of fiction read privately. Forms of learning that take place outside formal educational settings are sometimes categorised as public pedagogies. There is no agreed definition of this term. Sandlin, Schultz, and Burdick refer to its 'multi-faceted meanings' and 'historical contexts, theoretical transitions and various situations of practice' $(2010,2)$ in their edited collection. The analysis in this paper sits within the sub-category they label 'Pedagogies of Popular Culture and Everyday Life', which includes engagement with cultural products as diverse as video games, film, television, social media and popular music. The impact of fictions in everyday life interests adult educators: Wright discusses the effect of the British TV series The Avengers on women's consciousness (2007) and of the British TV series Doctor Who on its fanbase (2015), whilst Jarvis and Burr (2011) suggest the TV series Buffy the Vampire Slayer helped viewers develop a nuanced approach to moral judgements. Jubas's (2005) work argues that fiction can stimulate awareness of issues such as globalisation. Jubas and Knutson examined medical students' engagement with the fictional world of a popular medical drama and discovered it raised awareness of 'how aspects of social identity influence educational and professional opportunities and, potentially, outcomes' $(2013,237)$. Lawrence and Cranton (2015) examined how we may learn through imaginary dialogue with fictional characters about their ideas and motivations.

I now discuss the theoretical lenses informing the analyses: critical feminist pedagogy and reader-response theory. Brookfield (2005) discusses the relevance of critical theory to adult education, summarising the Frankfurt School's understanding that 'the central learning task of adulthood' is the 'critical distancing from, and then oppositional re-engagement with, the dominant culture' (13). Critical feminist theory extends this interest in unmasking power and the mechanisms which sustain power from a focus on class and capitalism to one which centres on gender and patriarchy and foregrounds the intersection of different structures of domination, such as class, race and gender (Light, Nicholas, and Bondy 2015); hooks refers to a 'mutually illuminating interplay of anti-colonial, critical and feminist pedagogies' which has enabled her to develop a pedagogy that that interrogates 'biases in curricula that re-inscribe systems of domination' $(1994,10)$. Luke and Gore $(1992,1)$ speak of feminist educators' commitment to clarifying 'how realms of domination subordinate subjects marked by gender, ethnicity, race, class, sexuality.'

Adult educators identify envisaging alternative ways of being as integral to this work of critical and transformative education. Brookfield (1987) discusses the power of imagining alternatives and Mezirow refers to the importance of resisting 'unexamined cultural norms' (2000, 30). Feminist educators explore this idea of alternative ways of living to undermine patriarchal norms. Patti Lather, building on Gramsci, talks about developing a counter hegemony through critical curriculum to 'present alternate concepts of reality' $(1984,55)$. This informs my understanding of the work done by a novel such as The Power, in which an alternative, womendominated society appears as difficult to challenge politically and intellectually as patriarchy often seems to be today. 
Feminist scholars have also sought to integrate critical feminist theory with poststructuralist thinking, including Butler's (1993) conceptualisation of gender as a performative process, and Foucault's (1997) discussions of power, knowledge and disciplinary power (Allen 2013, 2015; Weir 2013). I view The Power through a critical feminist lens to show how it names and unmasks the subordination of women but also, suggest, in line with Butler's thinking, that it demonstrates gender can be disrupted, as it is performative and situated, shaped by repetitive acts over time. The Power is a particularly contemporary novel because it moves between a critical materialist understanding of experience and poststructural recognition of the discursive and tangential nature of that same experience. Close reading shows the novel presents power as both material and discursive. By focusing on the complexities of lived experience shaped through relationships, work, family, politics, technology and culture, it reveals the operation of power and the construction of identity, showing that maleness and femaleness are both material and discursive. In materialist terms, male and female are physically differentiated via the 'skein', and the superiority this confers results from political struggle, aided by physical and violent coercion supported through the hegemonic operations of mass communication media. At the same time, the novel challenges the progressive accounts of history that Allen (2015) notes are often associated with critical materialism. The convincing portrayal of a takeover of power reveals 'lines of fragility and fracture [within current] states of domination' (Allen 2015, 525) - male hold on power appears relatively tenuous and subject to multiple modes of resistance and disruption. Moreover, in this novel, the empowerment of women is predicated on the oppression of men, challenging progressive and essentialist assumptions that the empowerment of women will inevitably lead to a better world. The bodily symbol of power, the skein itself is material but also symbolic and discursive. Skeins may appear to define women physically, and their lack to define men, but these demarcations are socially constructed, as the few men born with skeins are shunned and punished; a neat literary example of Butler's configuring of sex as something that we do/perform, rather than something that we are. My analyses reflect this postructuralist insight, but also acknowledge, with Plain and Sellers (2007, 213), that literary criticism has come to appreciate that discourse is not everything: the linguistic body has not obliterated the material body.' The Power is a novel which shifts lenses, presenting reality as both material and discursive and therefore I draw on both materialist and poststructuralist concepts when considering the text.

I now explain how the position I take with respect to reader-response theory complements the critical feminist pedagogy by considering how critical feminist pedagogy operates in the context of reading a literary text. I consider how the literary and rhetorical work of a writer can expose the social construction of gender and gender relations and foreground these, whilst leaving space for individual 'voice' and deliberation in the reader. The Power uses literary strategies to distance readers from normalised assumptions about gender relations. In order to understand this process better, I draw on reader-response theory which foregrounds the active role of the reader in the making of meaning.

Literary theorists recognise that meaning is not created by authors' intentions but emerges when texts are read (Rosenblatt 1938, 1978). Many acknowledge, however, that the 'Death of the Author' as famously suggested by Roland Barthes (1967/1977), is exaggerated (Enos 1990). Enos argues that the writer's 'dialogic activity ... invites the reader in the first place, to create meaning' $(1990,341)$. Literary criticism considers this dialogic activity - the textual strategies writers employ to communicate the ideas and feelings they want to share. Authors write perhaps for what Booth (1983) called the implied reader, who will understand their frames of reference. A writer's ideas and the way they are conveyed constitute, in educational terms, the writer's curriculum. The term 
curriculum in the context of fiction refers both to the content that the teacher/author seeks to convey, and to teaching methods - the literary techniques and strategies employed to help achieve this end (Jarvis 2017).

Adopting this perspective on literature makes it possible to acknowledge that the deliberate feminist pedagogical strategies employed by the writer - the literary techniques she uses - reveal operations of power and function as feminist curriculum. At the same time, taking a readerresponse perspective does not position her readers as passive recipients of her 'message'. It allows space for the impact on women's reading from the texts of their experiences and from their critical engagement. There is a tension in all forms of critical adult education, including feminist education, between the 'critical distancing' and 'oppositional re-engagement' that Brookfield $(2005,13)$ describes and the democratisation of the teacher-learner relationship. Feminist pedagogies pose difficult questions (Markowitz 2005; McCusker 2017) - they do not impose the teacher's views. Similarly, literary texts provide opportunities to challenge hegemonic positions on gender without determining the reader's final interpretation of the politics or the text itself.

\section{Methodology}

\section{Analysing the novel}

I undertook a close reading of the novel to identify techniques Alderman uses to convey her feminist beliefs. Originally associated with I. A. Richards (1929) and William Empson (1930), close reading attempted to disassociate text from context and derive meaning through scrutiny of form, technique and structure. Its value is that assertions of meaning have to be grounded in evidence from the text; its limitations are its decontextualisation, which means that in its purest form it is incompatible with critical feminist pedagogy that would locate fiction in its historical and political context. Close reading is, however, a useful foundational process for identifying textual practices that can then be understood in a broader context. It is compatible with a discussion of literature as a form of pedagogy because it uncovers the mechanisms - the forms of rhetoric, the telling of a story from a particular viewpoint, the use of semantic fields with specific connotations, the structural devices which act pedagogically upon readers.

I read inductively, prior to reading the Mumsnet discussion, noting key ideas. Coding identified interrelated themes appropriate for feminist analysis: economic exploitation, the family, violence and sexual sadism, the relationship between human rights and national security, and gender and the arts. I decided to focus on a structural device, the pervasive use of gender reversal, which Alderman uses to foreground the abuse of women in contemporary society:

people call it a dystopia. But. Nothing happens to a man in this book that isn't happening to a woman somewhere in the world right now. I promise. So... if this is a dystopia, does that mean we live in a dystopia right now? I think probably yes.

I chose, as examples of this gender reversal, Alderman's use of letters to frame the novel and the use of violence against men. 


\section{The Mumsnet discussion}

Internet research raises ethical questions, particularly when obtaining consent is not possible. The AoIR's Ethics Working Committee recognises that internet ethics cannot be subject to set rules, stating, 'ambiguity and uncertainty are part of the process' (Markham and Buchanan 2012, 5). Addressing underlying principles is critical. Based on general ethical principles, including those set out in the AolR document, the relevant questions here are the status of the data as public or private, the legal right to use it, assessment of the vulnerability of participants and of any potential harm, the purpose and value of the research, and the extent to which the data is used for purposes markedly different from those intended by participants. I was also mindful of the need to treat posts respectfully. I will address these points individually. First, I draw attention to precedent.

There is precedent for reproducing and commenting on publically accessible internet sites without permissions. Seale et al. (2010) conclude such messages are in the public domain and that informed consent is unnecessary. Pederson and Smithson (2013) analyse the use of Mumsnet specifically, recognising that it is not feasible to obtain informed consent for material in this forum because 'users post under user names and not all choose to accept contact from others ... so contacting each poster quoted for informed consent is not possible.' This is the case with respect to the posts I accessed: online posters change regularly and are not necessarily around once a specific discussion has ended. Mumsnet posters know posts are public. Mumsnet itself uses quotations from discussion boards in their publications, so users know they may be quoted in other publications: 'Mumsnet is an open-access public forum, and users are advised of this fact and that postings are open for all to see' (Pederson and Smithson 2013, 99). Other publications, such as Cochran (2014), use quotations from internet fora without seeking consent. The copyright position is that it is permissible to extract and quote from such data for non-commercial research.

Although there is precedent for using publically available internet data, adhering to underlying ethical principles is essential. An overarching ethical principle is that research should do no harm. I considered potential harm from the ability to attribute data to individuals. I use the usernames chosen by contributors. Some names are clearly fictional; others might identify contributors. However, contributors choose their names for a public forum, which is likely to receive more readers than an academic journal; my work does not increase the likelihood of recognition. I have been respectful in my analyses. I examine how reading stimulates women's reflections on issues relating to gender; I do not critique contributions or make derogatory comments. My analysis is less intrusive than that of Pederson and Smithson which discusses the social and educational class composition of Mumsnet posters.

This is not an identifiably vulnerable group. Participants enter a public discussion forum in order to converse - posts are intended to elicit response and consideration. Whilst contributors would not anticipate that someone might look at their responses to determine the educational impact of reading, my examination of how reading the text prompted critical reflection on gender issues aligns with the reasons they posted and the ideas they wanted to consider: they examined The Power with respect to gender, and discussed its impact on them with each other and with the author; I examine how The Power operates as a form of critical feminist pedagogy with respect to its content and teaching strategies. Finally, whilst the research does not directly benefit participants, it demonstrates the value and stimulation reading brings to people's lives. I obtained approval for this work from my institution's research ethics committee. 
The online discussion was 24 pages long, making manual coding possible. I highlighted words and sections relating to the operation of texts as critical feminist pedagogy. I assigned preliminary codes, refined through repeated readings, and combined these findings with themes from the analysis of the novel, to come to the final three areas for discussion: Alderman's selfidentification as a feminist educator, the use of gender reversal to illustrate how this artistic strategy works as pedagogy, and the way readers feel challenged by reading the novel to reflect on gender and its significance for them. Data for the first and last categories come primarily from the Mumsnet discussion. The section on gender reversal is the longest and combines data from the discussion and the close reading of the novel.

The Mumsnet posts are reproduced verbatim - including spellings and punctuation. Omissions are indicated by ellipsis. I refer to discussion participants as contributors (reflecting their writing role) or readers.

\section{Findings}

\section{Alderman as feminist educator}

Alderman's contributions to the Mumsnet discussion show that she wants to encourage engagement with feminist concepts. The reception of these ideas by readers indicates those intentions are often fulfilled. At the same time, the readers' comments also indicate that they actively make meaning from her work - they build on her ideas, make connections with their existing frames of reference and do not always interpret as she might hope. Alderman deliberately developed The Power as her feminist vehicle:

I came up with a premise that I thought talked about what I wanted to talk and think about... and then I let the premise do the work. There's no need to insist on the symbolism/metaphor: it's baked into the story. I also do like an exciting story, so I thought l'd write one, to help my feminist/ gender theory go down ;-)

Like teachers, she designs learning for a diverse group: she realised some readers might needed additional signposting to understand the point. The literary device of the letters between the archaeologist, Neil, and the writer, Naomi, supports readers needing extra direction:

I love them, but I knew that for some readers they'd be too obvious but for others not obvious enough.

Alderman talks about challenging all forms of essentialism, even those which present women as less cruel and more responsible than men. When asked what reaction she wanted when she wrote The Power she acknowledges her goals may seem extreme:

Total revolution of the ideas of gender of everyone in the world. Acceptance that there's no such thing as a 'male personality' or a 'female brain'. I like a bit of ambition. 
She is open about her work being purposefully political: when asked if she is a feminist, she replies:

Certainly am a feminist. I get very angry about almost all of the issues. I am PASSIONATE about encouraging women to be MORE AMBITIOUS for themselves and their careers and their lives ... I am also PASSIONATE about how much the gender binary hurts men as well as women.

Just as adult/feminist educators have done (Lather 1984; Brookfield 2005), Alderman encourages imagining alternative worlds:

I am actually hopeful about the possibility that thinking and writing and debating and believing can make a difference. Otherwise I wouldn't have written a novel, I'd just have got myself an armoury ;-) ... I believe in the power of IMAGINING IT DIFFERENT)

Alderman's responses suggest that she wants her work to lead to action, not simply understanding. Her contributions make her teaching intentions clear, but contributors also show that they look to fiction for this kind of education. 'Lalamcbride' asks Alderman whether she was trying to get readers to think about the term Matriarch. 'Mamabear' asked her whether the book was her 'opportunity to speak up and remind us Women that while the book is fictional - we are incredibly powerful especially when we all come together.' Some readers also see fiction as a way to further a gender revolution:

I strongly believe that laying out this issue is a first step to a revolution on that field. (todormirchev)

In the absence of a sudden noticeable change in physical power, it is books like yours to provoke thought ... that are needed to 'fix it'. (southsidemum)

There was an instance of the novel promoting specific action:

I have two young daughters ... My 7 year old came home from school ... telling me how angry she was that the boys in her class kept showing off that boys were better than girls that they were stronger and could do more things than her. With your novel in my head ... I told her to take that anger and use it to show them that there wasn't anything she couldn't do if she put her mind to it ... In another time maybe I would have told her not to be 'angry' or to just to ignore it ... (mamabear)

In response to being asked whether she feels it is inevitable that women will be abused 'just because men can' (Destinysdaughter), Alderman argues that we can resist: 
I tell you what I'd like to see just for starters. Teach all girls self-defence, from the age of 5-16 instead of netball and rounders. Teach boys about non-violent ways to solve their problems.

She is committed to change:

The feminist movement has been one of the most incredibly effective (mostly) nonviolent movements for social change the world has ever seen. We can change things. ... Together, we are unstoppable.

Towards the end of the conversation, Alderman says that the discussion makes me so happy to know that [the book is] making people think and talk and get angry ... it's so easy to slip into complacency, and I guess if I wanted to do anything with this book, it was to make the familiar strange again.

\section{Gender reversal as artistic method}

This sub-section considers how Alderman encourages readers to 'imagine it different.' I focus on her use of gender reversal. This serves a primary objective of critical feminist pedagogy, the unmasking of the operation of power with specific reference to gender. It also illuminates, too, as is central to poststructuralist feminism, the concept of gender performativity, by showing how gender subsumes sex through the repetition of bodily acts. Two literary strategies based on gender reversal are explored in detail - descriptions of violence and the use of letters as a framing device.

Violence, objectification, submission

The novel graphically depicts violence perpetrated against men by women, which shocks because unfamiliar. Women's skeins enable them to kill by touch and rape men to death. Initially women use 'the power' to punish abuse or escape danger. Roxy uses it against gangsters who kill her mother; Allie kills her abusive stepfather; and women in Saudi Arabia respond to the beating to death of two girls. Gradually, though, violence against men becomes routine. Girl gangs humiliate, rape and injure boys. Schoolboys fear attacks from girls. By focusing on physical violence Alderman draws attention to the interplay between materiality (the physical impact of the skein) and the social construction of power (changes in power dynamics and discursive frameworks). Male subordination is embodied in acts such as forcing a male waiter to lick up broken glass along with brandy for speaking when a woman is speaking. The female president uses this act to teach him his value as a man - 'this bottle is worth more than you' (229). I referred earlier to Butler's suggestion that sex is created by the things we do - performed and reinforced through repetition. Her proposition that 'Sex is an ideal construct which is forcibly materialized through time' $(1993,1)$ can be seen in the way repeated violent acts create the idea of male and female. The discussion and interpretation of gender through language and through repeated acts of violence, rather than the presence or absence of a specific body part - the skein - confers power. Although women's domination is 
explained and justified by the possession of the skein, the skein itself is constructed through repeated acts and discursive processes. For example, Roxy's brother Darryl steals her skein and has it transplanted into his own body but is torn apart by furious women, outraged at this seizing of women's rightful power. A boy born with a skein is considered a freak and is socially ostracised. As Butler states, exclusionary practices are part of the 'matrix of gender relations that institutes and sustains the subject' (9) and here, even men with the same physical qualities as women are excluded from power.

Alderman shows how violent repressive practices work alongside the ideological work of the media whose platforms partially legitimise groups, countries and communities that say:

Men are dangerous. Men commit the great majority of crimes. Men are less intelligent, less diligent ... Men are more likely to suffer from diseases and they are a drain on resources ... Of course we need them to have babies, but how many do we need for that ... how many is that ... Maybe one in ten. (278)

The relationship between gender and the operation of political and economic power is foregrounded when Alderman describes how in Bessapara, it is decided that men must have a female guardian, just as currently women in Saudi Arabia must have a male guardian whose permission they need to marry, divorce, travel or work. Men must surrender their passports, cannot drive or own businesses. Tunde is in Bessapara when these things are decreed. He is captured by a mountain tribe that sacrifices men. The violence accelerates when another tribe attacks his captors. The attacking women send electricity through eyeballs, mutilate genitals and murder children, whilst relishing the slaughter. Readers found this deeply shocking, but it served its purpose. Their initial horror shocked them into realising that this apparently unbelievable violence is perpetrated against women in our world:

There are some breathtakingly upsetting and violent scenes but I felt they were entirely justified. What will stay with me is that every time something happened that seemed far-fetched or too horrific, I was immediately hit by the sobering and horrifying fact that something like it was already happening to women somewhere in the world.

(Daimbardiva)

Hygellig's comment shows how the violence challenged her assumption that women would not be as abusive as men if they held power, but she continues to believe a kinder society will evolve:

the basic idea was interesting in terms of what it would mean for society and the changing roles and status of men and women. It was quite disappointing that it ended up in female abuse of men and a major war. ... maybe after the Cataclysm Era a more peaceful society developed, if not an equal one. 
Similar reflections came from Destinysdaughter, who shows an emerging engagement with the idea of power and its corrupting potential:

does that mean that women are doomed to experience oppression just because 'men can'? Also, I'd like to believe that, if women were in control, we would create a much kinder world ... Are we no better than this? ...

The strategy did not work for everyone though: Blatherskite commented 'the men are nothing but evil bastards and target practice. Seems sexist but in reverse.'

\section{The framing device}

Alderman employs a framing device in which a female writer (Naomi) patronises a male author (Neil). The letters draw attention to male subordination. Neil's address is 'The Men's Writers Association'. This jars. In our society it is women who need named prizes and support groups. His tone is self-deprecating: he sends it 'in the hope' that Naomi will 'give me some guidance, or at least that I'll finally hear the echo of it as I drop the pebble of this book down the well' (ix). He apologises for speaking: 'Anyway, sorry, I'll shut up now'; his junior status limits his right to speech and opinion. Naomi's patronising response reinforces his lowly status. She begins, 'Dearest Neil'. Although she has only skimmed his work, she calls it 'a treat', trivialising it, as indulgence rather than art. She uses the demeaning term 'saucy boy' because he includes scenes with 'male police officers' and 'boy crime gangs' and adds 'I don't have to tell you how much I enjoy that sort of thing. ... I'm practically on the edge of my seat' $(x)$. These responses mirror contemporary responses to women in male dominated roles in which they become fetishised, diminishing the impact of their erosion of male territory. It takes Neil's careful attempts to make a serious point about gender, power, and the shape of history, and turns it into sexual titillation. Naomi comments that her partner will leave her for 'some woman who can write' if her new book is not a masterpiece -men are the gold-diggers, getting money and status through association with powerful women.

The letters illuminate the performative and discursively constructed nature of gender: centuries of repetition of humiliating and subordinating bodily acts have led to a collective belief that the dominance of women is grounded in male and women's biology and psychology. Naomi says she would like to live in the pre-Cataclysm world in which men held power, because she is convinced this would have been 'kinder, more caring, and - dare I say it? - more sexy' ( $\mathrm{x})$. This neat use of irony relies on readers knowing that their own male-dominated world is far from kind. Naomi's comment mirrors contemporary claims that there would be no wars, better corporate practices, and kinder politics if women were in charge and so draws attention to these essentialist assumptions.

At the end of the novel, another exchange of letters reinforces this challenge to essentialist thinking. Essentialist/biological arguments are introduced to support stereotyping men as naturally subordinate and gentle, just as they are currently used to sustain the subordination of women. Naomi writes:

I feel instinctively ... that a world run by men would be more kind, more gentle, more loving and naturally nurturing. Have you thought about the evolutionary psychology of 
it? Men have evolved to be strong worker homestead-keepers, while women - with babies to protect from harm - have had to become aggressive and violent. (333)

Significantly, this letter appears at the end of the book, when readers have already observed women's aggressive capacities through the reproduction of individual and collective acts of cruelty and its justification through discourse presenting the coercion of men as necessary for the success of humanity. Feminist pedagogy relies on challenging assumptions about the relationship between bodily materiality and gender, as Alderman indicated when she stated that she wished to challenge the idea of the male and female brain. The framing by these letters illustrates how the same physical evidence, that women bear children, often presented in contemporary society as constitutive of a yielding, gentle character, is reversed through discursive practices and used to support the claim that women are naturally aggressive.

The hegemonic power of education and received opinion is demonstrated through the fact that even Neil, who attempts to review and revise the past, thinks women could never have been treated as badly as men are. He cites the routine abortion and genital mutilation of boy babies, arguing it would never have made sense for cultures to interfere with women's reproductive organs. This is deeply ironic, as readers know that genital mutilation of girls is common today, that girls are aborted and girl babies left exposed to die. The letters reinforce the conclusion that gender roles are rooted in power differentials not biological necessity.

The letters also draw attention to the ideological and hegemonic power of state education in reinforcing inequality: Naomi undermines Neil's thesis by noting that schools teach there is no evidence women ever lacked skeins or men held power. She cites received explanations for artefacts showing male warriors, which say these prove that men occasionally fought to entertain women. Neil counters with the sheer volume of artefacts found, and tellingly notes that this evidence has been ignored, whilst the established view of the past is maintained. Some found the device of the letters too obvious: MOstlyHet wrote

I was very conflicted about the trick of using the framing device of having an imaginary mere male author write a work of historical fiction, and having the female publisher womansplain what she was doing to him. ... it so neatly skewered and inverted so many such earnest discussions I've seen in the real world. ... did step over the line from letting the reader work out the political message for herself into spelling it out for her

Others found the letters stimulated reflection: 'The letters at the beginning and ending of the book just made the whole thing more thought provoking' (SallySwann).

\section{Reflecting on gender}

The book made readers think deeply and question their values and assumptions, describing the reading experience as emotionally disturbing, painful and unsettling. Words like thought provoking, challenging and upsetting recur: 
it left me feeling quite uncomfortable and disturbed, not that I disliked it, it's just a good book for really making you think. (ElizaBenson)

Not all enjoyed this. One reader commented that she found it depressing to think that power always corrupts; another preferred reading to escape. Readers noted specific ways the novel had made them think, including reflecting on the implications of having enhanced power:

It really gets you thinking about the world we're in now, and how we might act if the power was balanced in a different way. ... We may all think we would do things better, but in that situation perhaps not. (MrsRedWhite)

The contributor below demonstrates that the book has made her think about her actions:

I really enjoyed the paths my mind wandered along and the questions I started asking myself while reading this novel. Would I go along with the crowd? Would I let the power get to me? (pbandbacon)

This suggests reading privately can provoke deep personal reflection, linked to political awareness. Reading deeply engaging fiction may help readers understand that everyone has the potential to abuse power, rather than assuming they could never be oppressors. Adult educators have argued that understanding our own capacity to abuse power is as important as understanding ourselves as oppressed, or understanding the perspective of people experiencing oppression. Tisdell (2008), for example, notes discussions about the movie Crash made some students more conscious of their own racism. In the case of The Power, the violence perpetrated by women stimulated some readers to question their views about gender and power:

I have spent a lot of time pondering if there are any circumstances in which patriarchy wouldn't be the dominant model and I find it hard to image any. Can you envisage a situation where women become dominant without a physical advantage, like in the power? (DeviTheGaelet)

Readers made connections between The Power, wider political issues, and other texts, referring to feminism, other texts (Disney's Frozen and the writings of Esme Dodderidge), to transdebates, sociology, matriarchy and current politics. Reading encouraged them to take mental journeys, wandering between different ideas and their implications for their own context. This aligns well with Alderman's intention that readers should reflect on their reading and its relationship to their own experiences:

I chose a few stories and hoped that readers would ponder their own, and how this world would be for them. 


\section{Conclusion}

Learning that takes place in every-day life, such as fiction reading, constitutes a significant portion of learning for adults, particularly in an economic and social climate in which diminishing adult education budgets have reduced opportunities for critical conversations in many countries, by redirecting resources to narrowly vocational/technical education.

This paper argues that The Power stands as a piece of critical feminist adult education. Analysing it contributes to understanding the textual and hermeneutic processes which operate to enable fictions to function as pedagogy. The discussion of the Mumsnet conversation complements the analysis of the text and gives richness to the claim that reading fiction is an educational process. The conversation between Mumsnet contributors and the author reinforces the categorisation of writing fiction as a pedagogical act, revealing the educational intentions of the author and the willingness of readers to see fiction reading as an educative process. It shows how reading the book privately, prior to the discussion session, has drawn readers' attention to specific aspects of feminist thought and caused them to reflect on the relationship between these and other aspects of their lives. I have not attempted to demonstrate how the online discussion operated as a learning process, although it may be that awareness of the upcoming discussion prompted readers to think particularly carefully about the novel. This specific discussion occurs within a short time frame which does not offer sufficient material to make a thorough analysis of learning through online discussion. It does point the way to the potential for further exploration by adult educators of discussion forums in which individuals challenge and critique each other's perspectives. There is a growing literature examining online discourse, but it is not extensively developed from an adult and continuing education perspective and tends to focus on opportunities developed by educational institutions.

Analysing the text from an educational perspective identified curriculum content and teaching processes. The novel reveals the socially constructed nature of gender, and gendered forms of power and oppression. It shows in detail how power operates through a complex mix of fear, insecurity, greed, prejudice and a desire for revenge. It embeds feminist theory into a story told from multiple perspectives, offering opportunities for engagement with characters caught up in a dramatic social change - the reversal of male female power. It confronts readers with their own assumptions about gender and foregrounds the importance of both discourse and of structural and material power. Analysing fictions such as The Power shows fictions have the potential to promote critical thought, unaided by educational institutions or teachers.

\section{References}

Alderman, N. 2016. The Power. New York: Viking Press.

Allen, A. 2013. "Feminism, Foucault, and the Critique of Reason: Re-reading the History of Madness." Foucault Studies 2013 (16): 15-31.

Allen, A. 2015. "Emancipation without Utopia: Subjection, Modernity, and the Normative Claims of Feminist Critical Theory." Hypatia 30 (3): 513-529.

Barthes, R. 1977. "The Death of the Author." In Image Music Text translated by S. Heath, 142-148. London: Fontana. (Original work published 1967) 
Booth, W. 1983. The Rhetoric of Fiction. Chicago: The University of Chicago Press.

Brookfield, S. 1987. Developing Critical Thinkers. San Francisco: Jossey-Bass.

Brookfield, S. 2005. The Power of Critical Theory for Adult Learning and Teaching. Milton Keynes: Open University Press.

Butler, J. 1993. Bodies that Matter: On the Discursive Limits of "Sex". New York: Routledge.

Cochran, T. 2014. "By Beholding, We Become Changed: Narrative Transubstantiation and the Whedonverses." Slayage: The Journal of the Whedon Studies Association 11 (2)/12 (1).

Empson, W. 1930. Seven Types of Ambiguity. London: Chatto and Windus.

Enos, T. 1990. "Reports of the 'Author's' Death May Be Greatly Exaggerated but the 'Writer' Lives on in the Text." Rhetoric Society Quarterly 20 (4): 339-346.

Eynon, R., and Helsper, E. 2011. "Adults Learning Online: Digital Choice and/or Digital Exclusion?" New Media \& Society 13 (4): 534-551. doi:10.1177/1461444810374789

Foucault, M. 1997. "Sex, Power, and the Politics of Identity." In Ethics: Subjectivity and Truth (Essential Works of Foucault 1954-1984; Volume 1), edited by Paul Rabinow, 163-173. New York: New Press.

Gouthro, P., and Holloway, S. 2013. "Reclaiming the Radical: Using Fiction to Explore Adult Learning Connected to Citizenship." Studies in the Education of Adults 45 (1): 41-56.

Green, M. 2013. "Teaching with Comics: A Course for Fourth Year Medical Students." Journal of Medical Humanities 34 (4): 471-476.

Hills, M. 2015. "The Expertise of Digital Fandom as a 'Community of Practice': Exploring the Narrative Universe of Doctor Who." Convergence: The International Journal of Research into New Media Technologies 21 (3): 360-374.

Hoggan, C., and Cranton, P. 2015. "Promoting Transformative Learning through Reading Fiction." Journal of Transformative Education 13 (1): 6-25.

hooks, b.1994. Teaching to Transgress: Education as the Practice of Freedom. New York, London: Routledge.

Jarvis, C. 2006. "Using Fiction for Transformation." New Directions for Adult and Continuing Education 2006 (109): 69-77. doi:10.1002/ace.209

Jarvis, C. 2017. "Popular Fictions as Critical Adult Education." In The Palgrave International Handbook on Adult and Lifelong Education and Learning, edited by M. Milana, S. Webb, J. Holford, R. Waller, and P. Jarvis, 991-1009. London: Palgrave Macmillan.

Jarvis, C., and Burr, V. 2011. "The Transformative Potential of Popular Television: The Case of Buffy the Vampire Slayer." Journal of Transformative Education 9 (3): 165-182. 
Jensen, K., and Helles, R. 2011. "The Internet as a Cultural Forum: Implications for Research." New Media \& Society 13 (4): 517-533. doi:10.1177/1461444810373531

Jubas, K. 2005. "A Fine Balance in Truth and Fiction: Exploring Globalization's Impacts on Community and Implications for Learning in Rohinton Mistry's Novel and Related Literature." International Journal of Lifelong Education 24 (1): 53-69.

Jubas, K., and Knutson, P. 2013. "Fictions of Work-Related Learning: How a Hit Television Show Portrays Internship, and How Medical Students Relate to Those Portrayals." Studies in Continuing Education 35 (2): 224-240.

Jubas, K., Taber, N., and Brown, T. 2015. Popular Culture as Pedagogy. Rotterdam: Sense Publishers. Kinsella, E. 2007. "Educating Socially-Responsive Practitioners: What Can the Literary Arts Offer Health Professional Education?" In The Arts and Social Justice: Re-crafting Adult Education and Community Cultural Leadership, edited by D. Clover and J. Stalker, 39-58. Leicester: NIACE.

Lawrence, R., and Cranton, P. 2015. A Novel Idea: Researching Transformative Learning in Fiction. Rotterdam: Sense Publishers.

Lather, P. 1984. "Critical Theory, Curricular Transformation and Feminist Mainstreaming." Journal of Education 166 (1): 49-62.

Light, T., Nicholas, J., and Bondy, R. 2015. Feminist Pedagogy in Higher Education: Critical Theory and Practice. Ontario: Wilfrid Laurier University Press.

Luke, C., and Gore, J., eds. 1992. Feminisms and critical pedagogy. New York: Routledge.

Markham, A., and Buchanan, E. 2012. Ethical Decision-Making and Internet Research: Recommendations from the AolR Ethics Working Committee (Version 2.0). Association of Internet Researchers (AoIR).

Markowitz, L. 2005. "Unmasking Moral Dichotomies: Can Feminist Pedagogy Overcome Student Resistance?" Gender and Education 17 (1): 39-55.

McCusker, G. 2017. "A Feminist Teacher's Account of Her Attempts to Achieve the Goals of Feminist Pedagogy." Gender and Education 29 (4): 445-460.

Mezirow, J. 2000. Learning as Transformation: Critical Perspectives on a Theory in Progress. San Francisco: Jossey Bass.

Mumsnet. 2017a. "About Us." Mumsnet. Accessed October 32017.

Mumsnet. 2017b. "Book of the Month January 2017 - The Power by Naomi Alderman." Mumsnet. https://www.Mumsnet.com/Talk/book_of_the_month/2805542-Book-of-the-monthJanuary-2017-The-Power-by-Naomi-Alderman?pg=1\&messages=25 
Pandey, S. 2012. "Using Popular Movies in Teaching Cross-Cultural Management." European Journal of Training and Development 36 (2/3): 329-50.

Pederson, S., and Smithson, J. 2013. "Mothers with Attitude - How the Mumsnet Parenting Forum Offers Space for New Forms of Femininity to Emerge Online." Women's Studies International Forum 38 (May-June 2013): 97-106. doi:10.1016/j.wsif.2013.03.004.

Plain, G., and Sellers, S., eds. 2007. Introduction to Part III. In A History of Feminist Literary Criticism, edited by Gillian Plain and Susan Sellers, 210-14. Cambridge: Cambridge University Press.

Richards, I. 1929. Practical Criticism: A Study of Literary Judgment. London: Routledge \& Kegan Paul. Rosenblatt, L. 1938. Literature as Exploration. New York: Appleton-Century Co.

Rosenblatt, L. 1978. The Reader, the Text, the Poem: The Transactional Theory of the Literary Work. Carbondale: Southern Illinois University Press.

Sandlin, J. Schultz, B., and Burdick, J., eds. 2010. Handbook of Public Pedagogy. New York, London: Routledge.

Seale, C., Charteris-Black, J., MacFarlane, A., and McPherson, A. 2010. "Interviews and Internet Forums: A Comparison of Two Sources of Qualitative Data." Qualitative Health Research 20 (5): 595-606.

Sedo, D. 2003. "Readers in Reading Groups: An Online Survey of Face-to-Face and Virtual Book Clubs." Convergence 9 (1): 66-90. doi:10.1177/135485650300900105

Tisdell, E. 2008. "Critical Media Literacy and Transformative Learning: Drawing on Pop Culture and Entertainment Media in Teaching for Diversity in Adult Higher Education." Journal of Transformative Education 6 (1): 48-67.

Weir, A. 2013. Identities and Freedom: Feminist Theory between Power and Connection. Oxford: Oxford University Press.

Wenger, E. 1998. Communities of Practice: Learning, Meaning and Identity. Cambridge: Cambridge University Press.

Wright, R. 2007. "The Avengers, Public Pedagogy, and the Development of British Women's Consciousness." New Directions for Adult and Continuing Education: Special Issue - Popular Culture and Entertainment Media 2007 (115): 63-72.

Wright, R. 2015. "Doctor Who Fandom, Critical Engagement, and Transmedia Storytelling: The Public Pedagogy of The Doctor." In Popular Culture as Pedagogy: Research in the Field of Adult Education, edited by K. Jubas, N. Taber, and T. Brown, 11-30. Rotterdam: Sense Publishers.

Wright, R., and Wright, G. 2013. "Investigating Sci-Fi and Horror for Critical Adult Education and Teacher Education: Learning International Perspectives and Valuing the 'Other'". International Journal of Innovative Learning and Leadership 1 (1): 6-12. 